www.jmscr.igmpublication.org

Impact Factor (SJIF): 6.379

Index Copernicus Value: 71.58

ISSN (e)-2347-176x ISSN (p) 2455-0450

crossref DOI: https://dx.doi.org/10.18535/jmscr/v6i5.02

Journal Of Medical Science And Clinical Research

\title{
Anti- inflammatory response of soft tissue injury using different doses of low level laser application. (Experimental study on Rabbits)
}

\author{
Assist.Prof. * Dr Hareth. H. Kaskos
}

MS.c Oral \& Maxillofacial Surgeon-Duhok Polytechnic University - Iraq-Kurdistan Region

\begin{abstract}
Aim of study: To evaluate the effect of different wave length of low level laser therapy on the degree of inflammation following soft tissue injury.

Materials \& Methods: Nine healthy rabbits aged (6-10) months, weights 1-1.5 Kg were introduced to surgical operation by incision of $2 \mathrm{~cm}$ of skin and subcutaneous tissue on the dorsum of rabbit, the animals were divided into three groups. The first group(control) applied the same surgical procedure but without laser irradiation, the second group irradiated by 650nm, the third group irradiated by $810 \mathrm{~nm}$, the exposure time was(1mint) at $2.5 \mathrm{mw}$ immediately after surgery and then at day 2,3,5,7 post operative days .The experimental animals were scarified at the subsequent postoperative days and the specimens were examined histopatholgically. Number of inflammatory cells were calculated statistically to assess the degree of inflammatory response.

Results: The animals irradiated with 650nm of laser were significantly differences in all post operative days compare to control but non significant differences in the group treated with 810nm of laser except in 7 postoperative days compare to control .Statistically comparison of both treated groups $(650,810 \mathrm{~nm})$ showed significant differences in all post operative days.

Conclusion: laser reduce the inflammation and enhance the healing by increase the inflammatory cells at wave length of $650 \mathrm{~nm}$ but induced damage (reduction of healing)at $810 \mathrm{~nm}$.

Keywords: different wave length, laser, soft tissue healing.
\end{abstract}

\section{Introduction}

The wound healing process is a complex procedure and it have three phases, the inflammation, proliferation and remodeling phase $^{1}$. Many methods have been advocated to shorting the time of the inflammatory phase to induce rapid tissue healing one of these is the stimulatory effect of low level laser therapy (LLLT) that is increased in the recent years. ${ }^{2}$

LLLT is the application of light, this light is typically of narrow spectral width in the red or near infrared (NIR) spectrum $(600 \mathrm{~nm}-1000 \mathrm{~nm})$, with a power density between $1 \mathrm{mw}-5 \mathrm{~W} / \mathrm{cm}^{3}$. different laser wavelengths have different depths of penetration into human tissue. ${ }^{4}$ It is typically applied to the injury for a minute or a few times a week for several weeks. ${ }^{5}$ Although the photobiological effect of LLLT on tissue healing is not fully clarified ,but it follow the first low of photobiology ${ }^{6}$.

In vitro and in vivo studies reported that stimulation of specific metabolic processes in healing wounds. which is their effect on cellular and vascular reaction the later cause Vasodilation 
is stimulated via Histamine,Nitric Oxide (NO) and increase of Serotoninin, resulting in reduction of ischemia and improved perfusion. promoting the blood supply by new angiogenesis beside that it decrease the area of necrosis that have been demarcated in reconstruction and plastic surgery by skin flap design which is widely used in maxillofacial surgery. ${ }^{7}$

At the cellular level acceleration of leukocytic activity results in enhanced removal of non-viable cellular and tissue components, allowing for a more rapid repair and regeneration process. Increased Prostaglandin synthesis,(Prostacyclin), has a vasodilating and anti inflammatory action with some attributes similar to Cox-I and Cox-II inhibitors. $^{6}$, photo stimulatory effects in mitochondria processes, which enhanced growth factor release, and ultimately led to cell proliferation (Bjordal et al. $)^{8}$. Acute inflammation will assist in limiting the scope and duration of the inflammatory event and accelerate of process minimize the pain and severity associated with it ${ }^{8}$. The application of single dose of wave length of LLLT have been reported their effect in various studies in that (Mihaela etal) $)^{9}$ claimed that the use of wavelength $635 \mathrm{~nm} 1 \mathrm{~h}$ postoperatively till day (10)subsequently induce rapid primary soft tissue healing by rapid shooting of alkalyne phosphatase to 100 to 200 times above physiological limits in the experimental in that of control group ${ }^{9}$.

The same results that observed by (Kaviani et al $)^{10}$ with the use of $(665 \mathrm{~nm})$ of LLLTat dose of 10 $\mathrm{J} / \mathrm{cm}^{2}$ enhance diabetic foot ulcer healing compare to control.The application of different wave length and their tissue response whether it is proportionally effect to induce tissue healing or not, of these (Hawkins and Abrahamse) ${ }^{11}$ recorded that the cumulative effect of lower doses $(2.5 \mathrm{~J} / \mathrm{cm}$ 2 or $5 \mathrm{~J} / \mathrm{cm}^{2}$ ) determines the stimulatory effect, while multiple exposures at higher doses $(16 \mathrm{~J} / \mathrm{cm}$ ${ }^{2}$ ) result in an inhibitory effect with more damage on his study by helium-neon (HeNe) $(632.8 \mathrm{~nm})$ laser irradiation. (Bostanciklioglu et a) $l^{12}$ claimed that high-dose radiation has an effect on tissue healing, showed that at high wave length of 1064- $\mathrm{nm}$ laser is needed to activate the autophagic mechanism. but tissue healing does not occur when low dose radiation is applied.

(Albertini et al) ${ }^{13}$ has been suggested that lowlevel laser therapy (LLLT) can modulate inflammatory processes by effects red laser irradiation with two different wavelengths (660 $\mathrm{nm}$ and $684 \mathrm{~nm}$ ) on carrageenan-induced rat paw edema. Another study to compare the effectiveness of four different laser wavelengths (660nm, 810nm,980nm, and 1,064 nm) on the healing of mucositis in an animal model of wound healing by investigating the expression of plateletderived growth factor (PDGF), transforming growth factor beta (TGF- $\beta$ ), and blood-derived fibroblast growth factor (bFGF). These findings suggest that 980-nm diode laser therapy accelerate the wound healing process by cell proliferation and fibroblast growth ${ }^{14}$.

\section{Matreials \& Method}

Nine male healthy rabbits were introduced in this experimental study, weight $1-1.5 \mathrm{Kg}$ with aged 610 months, The rabbits was health monitored according to recommendations by FELASA (Nicklas et al) ${ }^{15}$ enabling them social contact and free movement, the animals were divided into three groups:

Group I: The number of animals used in this group were(3)received the surgical procedure but without used irradiation and considered as control.

Group II: The number of animals used in this group were(3) received the same surgical procedure in group I but with diod laser irradiation at the wave length (650) $\mathrm{nm}$ for 1 mints.

Group III: The number of animals used in this group were (3) received the same surgical procedure in group I but with diod laser irradiation at the wave length (810) $\mathrm{nm}$ for 1 mints.

\section{Preparation of the animals to anesthesia}

The general anesthesia obtained by intramuscular injection of $50 \mathrm{mg} / \mathrm{kg}$ ketamine hydrochloride (Claris, India) with $5 \mathrm{mg} / \mathrm{kg}$ Xylazine (Sanofi, 
France) was given as an intramuscular injection to induce sedative hypnotic condition.

\section{Surgical procedure}

The operative fields was disinfected by Povidone iodine $10 \%$ and then shaved, incision of about $2 \mathrm{~cm}$ length parallel with long axis of dorsum rabbit by blade no. 11 ,full subcutaneous thickness of rabbit skin then the incised wounded was irrigated with normal saline and then was sutured by two stitches of 3/0 black silk suture, one stitch at the beginning and the other stitch one at the end of the incision. Fig (1)

\section{Irradiation of animal}

The laser device used in this study is diod Laser system class IV, beam power, $2.5 \mathrm{~mW}$ max, beam wavelength $650-810 \mathrm{~nm}$, power $4 \mathrm{~W} \max \mathrm{cw}$ at the source, Spot size $8 \mathrm{~mm}$,Operating voltage 100-240 ,Frequency 50-60 Hz, Current 0.7 A max. Fig (2). The time of irradiation is (1mint), immediately after surgery and at 2,3,5,7 post operative days. The beam is positioned in that it is perpendicular to surgical wound in the mid ways between both sutures that was placed at the beginning and the end of the wound. Fig (3)

\section{Assessment Method}

The cellular inflammatory response were evaluated histologically, include counting of the inflammatory cells infiltration by Grid of $10 \mathrm{~mm} x$ $10 \mathrm{~mm}$ dimensions .Assessment at day 2,3,5 and 7 postoperatively as described by Pretel etal ${ }^{16}$ :
Score (0)- inflammatory cells:--No cell in the one square of the grid .

Score (1) inflammatory cells -- cells $<25$ in the one square of the grid .

Score (2) inflammatory cells --25-50 cells in the one square of the grid.

Score (3) inflammatory cells-- 51-75 in the one square of the grid .

Score (4) inflammatory cells--- cells $>75$ in the one square of the grid

\section{Results}

Histopathological study of specimens examination according to the numbers of inflammatory cell. showed that there were significant differences $(p<0.005)$ between the control and Laser treated group(LTG)at the wave length $650 \mathrm{~nm}$ at $2,3,5,7$ postoperative days respectively as showed in Table (1), Fig $(4,5,6)$. While non significant differences $(\mathrm{P}>0.005)$ between control and LTG at the wave length $810 \mathrm{~nm}$ in the day $2,3,5$ postoperativelly but only significant at day 7 postoperatively as that showed in Table (2). Fig $(7,8)$. Statistical comparison between both treated groups by different wave length of laser showed that there were significant differences in all at $2,3,5,7$ postoperative days respectively at $(\mathrm{P}<0.005)$. Table (3).

Table (1): Comparison between Control and LTG at dose 650nm

\begin{tabular}{|l|c|c|c|c|}
\hline \multirow{2}{*}{$\begin{array}{l}\text { Postoperative } \\
\text { days }\end{array}$} & \multicolumn{2}{|c|}{ Control group } & \multicolumn{2}{c|}{ LTG 650nm } \\
\cline { 2 - 5 } & Mean & + SE & Mean & + SE \\
\hline 2 & 4.00 & +0.0 & 2.00 & $+0.00^{*}$ \\
\hline 3 & 3.33 & +0.33 & 1.33 & $+0.67^{*}$ \\
\hline 5 & 3.33 & +0.33 & 0.00 & $+0.00^{*}$ \\
\hline 7 & 3.00 & +0.00 & 0.00 & $+0.00^{*}$ \\
\hline
\end{tabular}

LTG_Laser treated group . *Significant at $\mathbf{p}<0.05$.

Table (2): Comparison between control and LTG at dose 810nm

\begin{tabular}{|l|c|c|c|c|}
\hline \multirow{2}{*}{$\begin{array}{l}\text { Postoperative } \\
\text { days }\end{array}$} & \multicolumn{2}{|c|}{ Control group } & \multicolumn{2}{c|}{ LTG 810nm } \\
\cline { 2 - 5 } & Mean & + SE & Mean & + SE \\
\hline 2 & 4.00 & +0.0 & 3.67 & $+0.33^{* *}$ \\
\hline 3 & 3.33 & +0.33 & 3.67 & $+0.33^{* *}$ \\
\hline 5 & 3.33 & +0.33 & 0.33 & $+0.33^{* *}$ \\
\hline 7 & 3.00 & +0.00 & 3.00 & $+0.00^{*}$ \\
\hline
\end{tabular}

LTG_Laser treated group . ** Non Significant at $\mathbf{p}>0.05$. *Significant differencceP<0.05. 
Table (3): Comparison between LTG 650nm and LTG at dose 810nm

\begin{tabular}{|l|c|c|c|c|}
\hline \multirow{2}{*}{$\begin{array}{l}\text { Postoperative } \\
\text { days }\end{array}$} & \multicolumn{2}{|c|}{ LTG 650nm } & \multicolumn{2}{c|}{ LTG 810nm } \\
\cline { 2 - 5 } & Mean & + SE & Mean & + SE \\
\hline 2 & 2.00 & +0.00 & 3.67 & $+0.33^{*}$ \\
\hline 3 & 1.33 & +0.67 & 3.67 & $+0.33^{*}$ \\
\hline 5 & 0.00 & +0.00 & 0.33 & $+0.33^{*}$ \\
\hline 7 & 0.00 & +0.00 & 3.00 & $+0.00^{*}$ \\
\hline
\end{tabular}

LTG_Laser treated group . $\quad *$ Significant at $\mathbf{p}<0.05$.

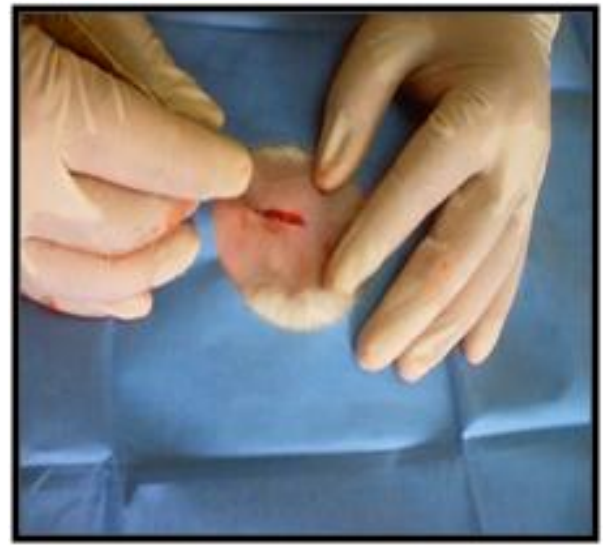

Fig (1)

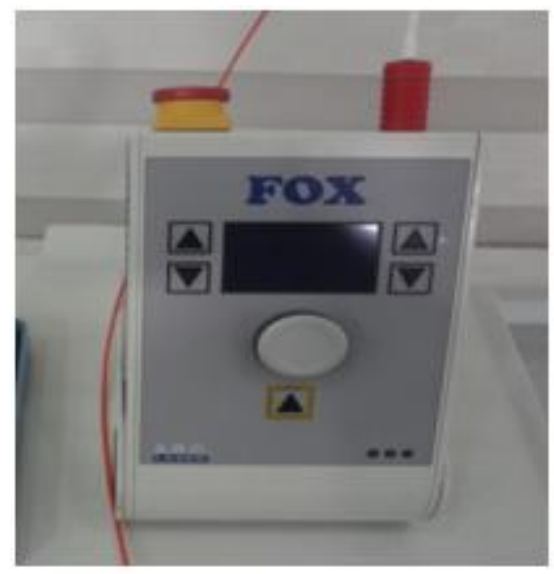

Fig (2)

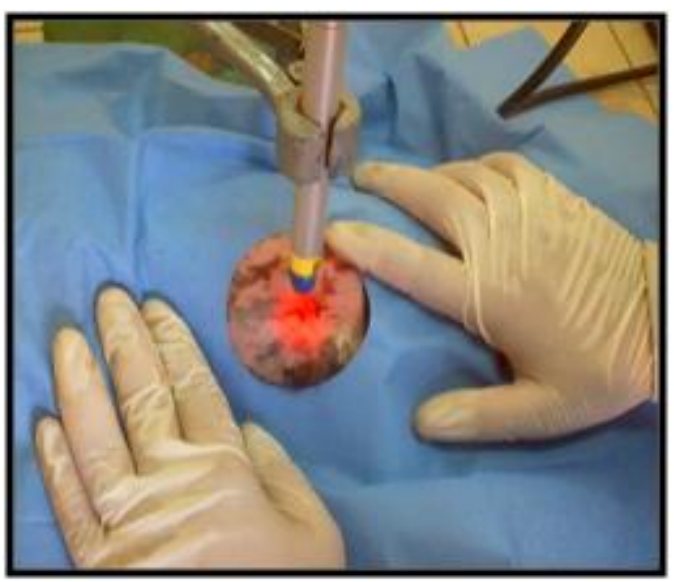

Fig (3)

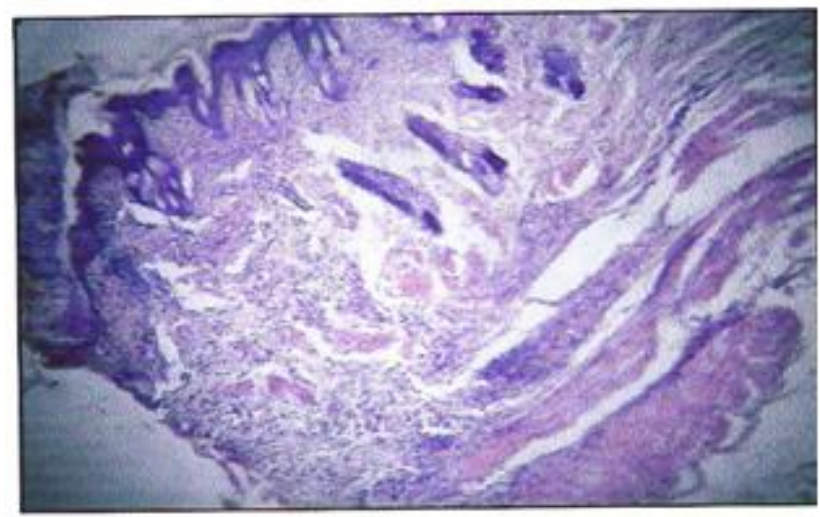

Fig (4) Controlled at day 3 postoperatively. extensive and diffuse inflammmatory cell infilitration of mononuclear cells (H\&E $40 \mathrm{X}$ )

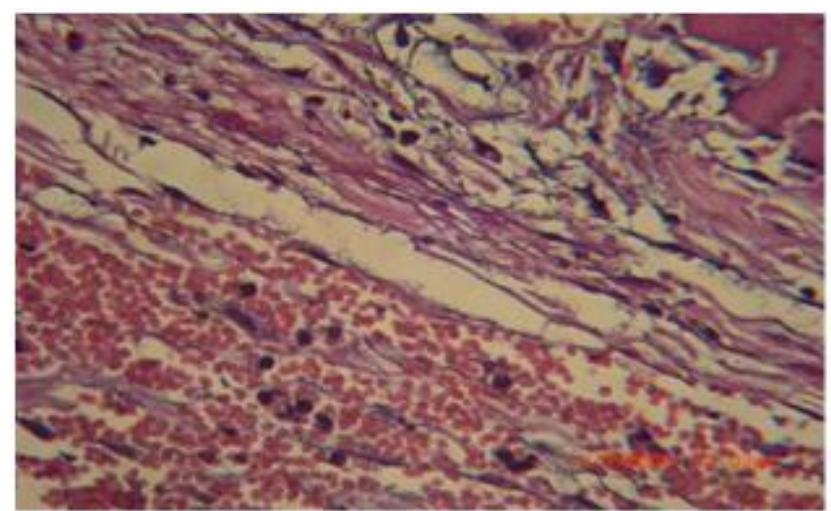

Fig (5) At day (3) with $650 \mathrm{~nm}$ with mild inflammatory cell infilitration (H\&E $40 \mathrm{X})$

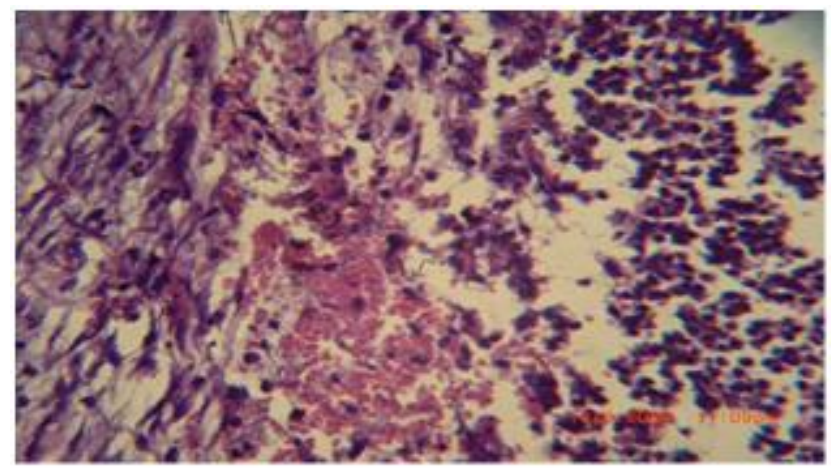

Fig (6) At day(3) with $810 \mathrm{~nm}$ with sever inflammatory cell infilitration. (H\&E $40 \mathrm{X}$ ) 


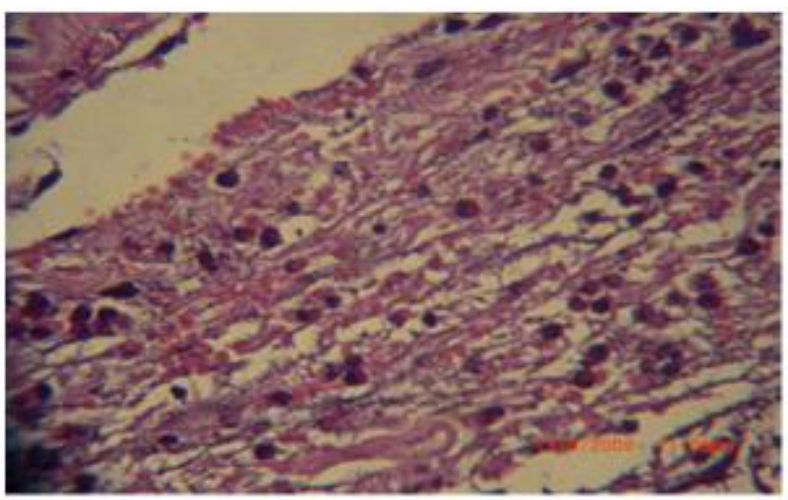

Fig (7) At day(3) with $810 \mathrm{~nm}$ with sever inflammatory cell infilitration. (H\&E $40 \mathrm{X}$ )

\section{Discussion}

As wound healing progresses through the stages of inflammation, proliferation, remodeling ,laser therapy presents the opportunity to impact each of these phases in positive and beneficial ways. It is extremely important that correct protocols are developed for laser therapy and that they include the use of appropriate wavelength, dose, potency density ,time of irradiation, as these parameters may have an influence on treatment .Beneficial effect of LLLT on wound healing can be explained by considering several basic biological mechanisms of these is induction of expression cytokines(responsible for the initial inflammatory phase of wound), increased both protein and mRNA levels of IL-and growth factors known to be responsible for the many phases of wound healing ${ }^{17}$. Our results with wave length $650 \mathrm{~nm}$ was in agreement with that Al-Watban and Zhang18, they report that irradiated with $650 \mathrm{nmm}$ laser light showed an inflammatory infiltrate increased and shorter resolution of the inflammation. this aspect can represent an antiinflammatory effect that might have initiated an early inflammatory response and that it was resolved more quickly than in the controls. The non significant results with increased in wave length $(810 \mathrm{~nm})$ on absorption by mitochondria they stimulate more ATP production and low level of ROS (--------------) which then activate the transcription factors such NF-B, to induce many gene transcript products responsible for the beneficial effects of LLLT. ROS are well known to stimulate cellular proliferation of low levels, but inhibit proliferation and kill cells at high levels 19 beside that cells irradiated at low wave length $(610 \mathrm{~nm})$ showed a higher degree of haptotaxis and migration as well as ATP luminescence as compared to cells irradiated at $(830 \mathrm{~nm}){ }^{20}$

Another conclusion reported by (Lubarter et al) ${ }^{5,21}$ , 22 in that Nitric oxide is also involved in LLLT, and may be photo-released from its binding sites in the respiratory chain and elsewhere. It is possible that NO release in low amounts by low dose light may be beneficial, while high levels released by high dose LLLT may be damaging, while increase the wave length and reduction of inflammatory cell infilitration by histopathological analysis compared to intense inflammatory one in control group

\section{References}

1. Antonio, PI.Gyselle, ME. Alessandro, VI.Darcy, AL.Carolina, CA.Jean, S.: Phototherapy improves healing of cutaneous wound in nourished and unnourished Wistar Rats. Braz Dent J.2004.Vol 15 .Special issue.

2. Mahesh. D.R. Padma,P. Chaya, M. David. G. Dinesh,D.: Photobiomodulation current concept and its application in dentistry .2013. International Journal of Dental Research, 1 (2) PP25-29

3. Kathrin, H. Beckmann, GM. And Sven,S.: Low Level Laser Therapy for the Treatment of Diabetic Foot Ulcers: A Critical Survey.2014.Evidence-Based Complementary and Alternative Medicine Vol 2014.

4. Richard,M. BS, CLT.: Laser-Accelerated Inflammation/Pain Reduction And Healing: Practical Pain Management, Nov/Dec 2003

5. Ying-Ying, H.Aaron, $\mathrm{CH}$. Chen, JD. Carroll, MR. Hamblin: biphasic dose response in low level light therapy. 2009. Inmternational dose response society. 
6. Sutherland JC.: Biological effects of polychromatic light. Photochem Photobiol . 2002.76:164-70.

7. Prado, RP. Pinfildi, CE.Liebano, RE. Hochaman, BS. Ferreira, LM.: Diode laser in viability of random skin flap in rats . 2005.Photomed Laser Surg 23:115.

8. Bjordal, JM. Johnson, MI. Lopes-Martins, RA. Bogen, B. Chow, R. and Ljunggren, AE.: Short-term efficacy of physical interventions in osteoarthritic knee pain. A systematic review and meta analysis of randomized placebo-controlled trials. 2007. BMC Musculoskelet Disord 8:51.

9. Mihaelac. toma,C. Marian, RC. : The effect of low level laser therapy on surgical wound healing. Romanian Reports in Physics, 2010.Vol. 62, No. 3, PP. 617627.

10. Kaviani, A.Djavid, GE.Ataie Fashtamil, L.Fateh, M.Ghodsi, M.Salami, M.Zand, N.Kashef, N.Larijani, B.:Randamized clinical trail the effect of low level laser therapy on chronic diabetic wound healing-preliminary report .Photo Med Laser surg.2011.

11. Hawkins, D.Abrahamse, H.: Effect of multiple exposures of low-level laser therapy on the cellular responses of wounded human skin fibroblasts. Photomed Laser Surg. 2006 Dec;24(6) :PP.705-714.

12. Bostanciklioglu, M. Demiryürek ,ŞCB. Demir,T,. Öztuzcu,S. Aras, MH. Özsevik, S. Usumez, A. Ergün, S. Özbal, HK. Bagci, C.: Assessment of the effect of laser irradiations at different wavelengths (660, 810,980 , and $1064 \mathrm{~nm}$ ) on autophagy in a rat model of mucositis. Lasers Med Sci. 2015 May;30(4):PP1289-1295.

13. Albertini, R.Villaverde, AB. Aimbire, F. Salgado, MA Bjordal, JM. Alves, LP. Munin, E. Costa, MS.: Anti-inflammatory effects of low-level laser therapy (LLLT) with two different red wavelengths (660 $\mathrm{nm}$ and $684 \mathrm{~nm}$ ) in carrageenan-induced rat paw edema.J Photochem Photobiol B. 2007 Nov 12;89(1):PP50-55.

14. Usumez, A. Cengiz, B.Oztuzcu, S. Demir, T. Aras, MH. Gutknecht, N: Effects of laser irradiation at different wavelengths $(660,810,980$, and $1,064 \mathrm{~nm})$ on mucositis in an animal model of wound healing. Lasers Med Sci. 2014 Nov;29(6):PP1807-1813.

15. Nicklas, W., Baneux, P.Boot, R. Decelle, T. Deeny, AA. Fumanelli, M., IllgenWilcke B; FELASA (Federation of European Animal Science Associations Working Group in Health Monitoring of Rodent and Rabbit Colonies) Recommendations for the health monitoring of rodent and rabbit colonies in breeding and experimental units. 2002.Laboratory animals 36, 20-42.

16. Pretel. H, lizarelli. RFZ, Ramalho, LTO: Effect of LLLT on bone repair histological study in rats.2007laserin surgery and medicine.39:788-796.

17. Poon,V.K. Huang, L.and Burd,A.: Biostimulation of dermal fibroblast by sublethal Q-switched Nd:YAG532 nm laser: collagen remodeling and pigmentation, J Photochem Photobiol B 81 (2005) 1-8.

18. Al-Watban FAH, Zhang XY.: The acceleration of wound healingis not attributed to laser skin transmission. Laser Therapy2000;12:3-11.

19. Corazza, AV.Jorge, J. Kurachi, C. Bagnato, V.: Photobiomodulationon the angiogenesis of skin wounds in rats usingdifferent light sources. (2007) Photomed Laser Surg 25:102-106

20. Kathrin, H. Beckmann, GMH. and Sven,S.: Low Level Laser Therapy for the Treatment of Diabetic Foot Ulcers: A Critical Survey. Evidence-Based Complementary and Alternative Medicine Vol 2014 , Art. 
21. Lubart, R. Wollman,Y. Friedmann,H. Rochkind, S.Laulicht, I.: Effects of visible and near-infraredlasers on cell cultures. J Photochem Photobiol 1992; 12:305-310.

22. Brassolatti, P.Bossini, PS.Oliveira, MC.Kido, HW.Tim, CR.Almeidalopes, L.Retto Dasilva DEA vol, Araujo-Moreira, FM.Parizotto,NA.:Comparative effect of two different doses of low level laser therapy on wound healing third degree burns in rats. 2016.Microse Res Tech. Feb(8). 